\title{
Sending parents outpatient letters about their children: parents' and general practitioners' views
}

\author{
Tony Waterston, Camille San Lazaro
}

\begin{abstract}
Parents' cooperation is essential to ensuring implementation of effective healthcare management of children, and complete openness should exist between paediatricians and parents. One method of achieving this is to send parents a copy of the outpatient letter to the general practitioner (GP) after the child's outpatient consultation. To determine the views of parents and GPs a pilot survey was conducted in two general children's outpatient clinics in hospitals in Newcastle upon Tyne. In March and April 1991 a postal questionnaire was sent to 57 parents of children attending the clinics, and a similar questionnaire to their GPs to elicit, respectively, parents' understanding of the letter and perception of its helpfulness, and GPs' views on the value of sending the letters to parents. Completed questionnaires were received from $34(60 \%)$ parents and $47(82 \%)$ GPs; $26(45 \%)$ respondents were matched pairs. $27(79 \%)$ parents said they understood all of the letter, $19(56 \%)$ that it helped their understanding, 32(94\%) felt it was a good idea, and $31(91 \%)$ made positive comments. In all, 29(61\%) GPs favoured the idea and six $(13 \%)$ did not. Eleven $(23 \%)$ said they would be concerned if this became routine practice, and $20(74 \%)$ of the 27 providing comments were doubful or negative; several considered that they should communicate information to parents. The views in the matched pairs were dissimilar: parents were universally in favour whereas many GPs had reservations. The authors concluded that sending the letters improved parents' satisfaction with communication, and they recommend that paediatricians consider adopting this practice.

(Quality in Health Care 1994;3:142-146)
\end{abstract}

\section{Introduction}

Information is important to patients, and doctors are often poor communicators. The outcome of a paediatric consultation can be improved by having a doctor who is friendly, takes time to discuss non-medical subjects, and offers information freely without patients having to request it. ${ }^{1}$ It has been suggested that information which helps understanding can reduce pain and speed recovery and that satisfaction about information received causes patients to comply with advice. ${ }^{2}$ Parents of children receiving care are in a special position as care givers in that they are not themselves the patient, although they know the history of their child intimately, and their cooperation is vital in securing effective management programmes, especially in emotionally or socially induced illness. It therefore seems natural that there should be complete openness in communication between paediatrician and parents.

One way of ensuring openness is to allow parents to see their children's medical records, ${ }^{3}$ and the rationale behind personal child health records ${ }^{4}$ is to improve communication and encourage a more balanced doctorparent relationship. Another method is to send patients copies of the general practitioner's (GP's) outpatient letter, and this has been evaluated. ${ }^{5}$ In paediatrics, Rylance has long been an advocate of this practice ${ }^{5}$ and has extended it to taping outpatient consultations and giving the parents the tape. ${ }^{7}$ In his study of copy letters, 222 of 224 parents who replied found the practice to be helpful and said that it made them less worried. GPs' opinions were not specifically sought, but three were unhappy with the practice, mainly because they thought a consultant's opinion should be exclusive to them. Rylance considered that sending copies to parents requires a willingness by doctors to modify their style of language but that the benefits greatly outweigh the disadvantages. However, it is still unusual for copies of letters to be sent to parents, and we suspected that one reason might be concern from general practitioners, as suggested by Rylance. ${ }^{5}$

We think that communication is often imperfect between consultant and parent and that it would be much improved by the transfer of written information, after the consultation. Indeed, improving communication between parents and doctors and then evaluating it is an important measure of quality of health care. As parent held records were about to be launched in Newcastle, we considered that it would be valuable for parents to have copies of letters to keep in the record. Before advocating the idea more widely we wished to canvass parents and GPs 
on their views since the letter is, after all, a confidential communication between hospital doctor and general practitioner. Previous studies have sought the views of patients but not those of GPs.

The aims of the study were (a) to elicit parents' views on their understanding of the letters and how helpful they were and $(b)$ to elicit GPs' views on the value of a copy letter being sent to the parents.

\section{Subjects and methods}

Consent to perform the study was obtained from the Newcastle Ethics Committee. The study population comprised the parents of children attending two general paediatric outpatient clinics in Newcastle upon Tyne over two months (March and April 1991). Most families attending CL's clinic were referred for problems arising from deprivation or poor care, as well as general paediatric problems. All parents seen were invited to participate, unless the consultant felt that for some reason it would be undesirable to send them a copy letter. In writing the letter, the consultants checked it carefully for readability and for the presence of sensitive information. At each consultation the parent or parents were invited to participate in the study, which involved being sent an identical copy of the letter that was sent to the GP. They were informed that a month later a questionnaire would be sent inviting their views. They were asked to contact the paediatrician or GP if they had any difficulty in understanding the letter or queries about its contents. At the same time a similar quesionnaire was sent to the child's GP asking for his or her opinion. The questionnaires and an anonymised sample letter are shown in the appendix.

\section{Results}

In all, 59 children were seen and 57 parents were recruited to the study. No parent declined to take part but two were excluded, one because of language difficulties and one because the letter contained sensitive third party information. Responses were received from $34(60 \%)$ parents and $47(82 \%)$ GPs, $26(45 \%)$ being matched pairs. No attempt was made to follow up non-responders.

The table shows the diagnostic groups of the children.

PARENTS' VIEWS

Of the 34 parents who responded $27(79 \%)$ said that they understood all of the letter, and

\section{Diagnostic groups of children seen}

\begin{tabular}{ll}
\hline & No \\
\hline Asthma & 9 \\
Soiling & 9 \\
Enuresis & 8 \\
Short stature & 8 \\
Urinary infection & 5 \\
Constipation & 5 \\
Behaviour & 4 \\
Epilepsy & 3 \\
Miscellaneous & $6^{\star}$ \\
\hline
\end{tabular}

*Down syndrome, trisomy 7, oesophageal atresia follow up, scabies, unexplained fever, developmental delay. only two had some difficulty: one admitted to seeking an explanation from a psychiatric nurse and the other mentioned checking a medical book. Nineteen (56\%) parents said that the letter helped their understanding a lot, and only one said it did not help her understanding (one did not agree with the contents of the letter). Thirty two $(94 \%)$ thought that this excercise was a good idea, one was opposed it, and one was indifferent. In all, 31(91\%) parents commented positively in the questionnaire; the box shows a representative selection.

\section{Selected comments of parents about receiving letter}

Excellent, makes parents feel more involved, besides keeping them fully informed

I think that every parent should be given a letter to explain the situation in all cases, because parents need to know all that takes place between paediatrician and GP

As a parent I like to know everything which concerns my child - so I can do my best to help them. Also it dispenses with the "secrecy" which surrounds doctors, clinics, hospitals, etc, and is a relic from days of old!

Being sent a letter which was also sent to my doctor gives me great satisfaction that you had the time and understanding for parents who sometimes don't understand. This is a very good idea

Until now I did not realise that when my child visits outpatients that my doctor is informed. I think it is a very good idea

Of the 23 non-respondents, 14 were later reviewed in the outpatient department on several occasions. All on questioning said that they welcomed the letter. Hence there was not an association between non-response to the questionnaire and negative views on receiving the letter.

\section{GPS' VIEWS}

Twenty nine $(62 \%)$ of the 47 GPs thought that it would be useful for parents to receive a copy letter, $10(21 \%)$ were indifferent, six $(13 \%)$ thought it undesirable, and two (4\%) said it depended on the situation. A total of $32(68 \%)$ GPs said that they would not be concerned if it became routine practice to send parents the copy letter whereas $11(23 \%)$ said that they would be concerned. Twenty seven commented in the questionnaire, and 20 of these comments $(74 \%)$ were doubtful or negative (see box).

\section{MATCHED PAIRS}

The box shows examples of comments in some of the matched pairs of GPs and parents.

\section{Discussion}

The main findings of this small pilot study were that most parents indicated that they understood the contents of the GP's letter and most said that it helped them to understand their child's problem. In contrast, many GPs 


\section{Selected comments of GPs about parents receiving letter}

Parents may experience unnecessary anxiety if there is medical jargon. How will sensitive issues be dealt with? In a separate letter to us only?

In all specialties patients often come to discuss hospital letters, often before letters have arrived. This is a waste of their time and of our time

There are other people in the family, all of whom need consideration. Therefore the interpretation of a hospital letter should be left to the GP

Bravo!! I feel there should be more openness in medicine

The parents would be less likely to return to us to discuss the outcome of the consultation, and continuity of care would be lost

Do you feel there is a case for the patient having a copy of the letter from the GP to paediatrician?

expressed uneasiness. Giving information is only one component of communication. This study did not attempt to measure parents' understanding of the information contained in the letter, though most parents thought that their understanding was increased.

The response rates to the questionnaires were fairly low. Only $60 \%$ of parents returned questionnaires, and this may have been a selected group who liked the idea. The clinics used in the study serve a largely working class population, and all social classes were represented among the responders. Previous studies showed that parents like to receive a copy letter; we were interested in the comments made by parents and in whether the idea was acceptable to GPs. The overwhelmingly positive comments made by parents, often in glowing terms, convince us

\section{Comments by matched pairs} $G P$

Child 1 Inappropriate to send identical letter to GP and parents in terms of understanding the problem and terminology used. Is this an excuse for poor communication in hospital outpatients?

Child 2 Certain problems could be interpreted wrongly by some parents

Child 3 Patients might not understand the content of the letter and be concerned

Child 4 I suspect it may limit the transfer of information between hospital and GP in some instances

Child 5 I think it would be of some limited value for a small section of parents
Parent

As a parent I like to know everything which concerns my children - so I can do my best to help them

I think it is a very good idea, as parents you feel less left out

Parents should know what the GP writes about their children, they should be involved a bit more. I think it is a very good idea

Being sent a letter which was also sent to my doctor gives me great satisfaction that you had the time and understanding for parents who sometimes don't understand. This is a very good idea. Thank you
Very good that most parents liked receiving the letter; certainly, no harmful effects were identified by parents or GPs in this survey (see below). We noted that 11 GPs reported parents visiting for an explanation whereas only one parent mentioned this. Non-responders may have consulted the GP, or some parents may have visited for discussion rather than an explanation. Of the 23 non-respondents, 14 werc later reviewed in the outpatient department and expressed positive views about the letter when asked about this by the consultant.

Interestingly, several parents hinted in their comments at their dissatisfaction with medical communication (for example, "it dispenses with the secrecy which surrounds doctors"), and there is probably general ignorance about the nature of the communication which takes place ("until now I did not realise that when my child visits outpatients, that my doctor is informed").

It is also important to address issues such as the doctor's manner, ability to listen, and avoidance of medical jargon ${ }^{1}$ as well as those of direct transfer of information.

Three reasons seemed to account for GPs' anxiety about parents receiving a copy letter: concern that the contents would be misunderstood, fear of creating parental anxiety, and loss of continuity of care if the parents do not receive an explanation directly from the GP.

Misunderstanding of contents - Some letters will probably be misunderstood, despite best intentions. Jargon and technical language should be kept to a minimum or a simple explanation given. If no follow up visit is arranged then contact with the GP should be recommended. Some GPs suggested that a separate, simpler letter, rather than an identical letter, should be sent to the parent, but this would considerably increase the labour of the task and in our view is unnecessary - indeed, many letters to GPs could be improved by being simplified.

Creating anxiety is certainly possible, although it did not apparently occur in our series of subjects. Parents need to be warned of the letter and offered the choice of declining; the letter should be composed with the parents in mind; and a contact number for discussion of the letter should be offered. Parents usually state that they would like to be given full information rather than being kept in the dark, and lack of openness is more likely to provoke anxiety than full but sensitive sharing of information.

Continuity of care - We suspect that only a few parents will normally see their GP after their child's outpatient consultation, so lack of continuity of care is a theoretical risk. Indeed, the fact that the parents have received a letter should help communication between parent and GP, since both have the same information and can discuss the implications more realistically.

We do not know how many parents normally visit their GP for discussion after their child's outpatient consultation, we suspect it happens only if a prescription is required or test results are to be given. Perhaps parents should be encouraged to visit the GP to talk about the 
letter and clear up any misunderstandings. Alternatively, the health visitor or school nurse could visit the home after a new outpatient appointment, to discuss the diagnosis and management issues.

We hope that GPs will eventually accept the idea of parents receiving copy letters when they perceive the benefit in parents' understanding that results. We feel that their disquiet is based on the view that sharing information fully with parents is undesirable and that some parents (perhaps those from lower socioeconomic groups) will not be able to handle the information. It would be valuable to analyse satisfaction by social class. We did not do so, but parents attending our clinics are predominantly from social class 3 or below; our experience indicated that parents with less education appreciate the letters very much as they are less used to open sharing of information.

From the hospital side, firstly, we suggest the exercise should not become routine in the sense of a secretary automatically copying a letter to a parent. Active thought needs to be given to the phrasing, and on some occasions a separate letter to the GP might be necessary. Secondly, parents should be given the choice of receiving the letter. Thirdly, they should be invited to ring the consultant or see the GP for discussion if they have any doubts or questions. The increase in work and cost should only be slight whereas in our view, the benefit in terms of parent understanding and confidence is very great. However, satisfaction as elicited in our study does not imply understanding, which would need to be determined differently. Satisfaction with the communication in an outpatient consultation nevertheless remains an important quality measure. Withholding a letter from parents because the contents are too sensitive might cause disquiet, but this seems unlikely. In such circumstances parents could be sent a personal, modified letter, or sensitive matters could be discussed with the GP by telephone. Our experience suggests that it is quite possible to allow parents to see copy letters even if they contain opinions which may be painful or difficult to accept, as long as the views are simply and honestly stated and balanced with positive comment. Straightforward communications on illnesses such as asthma and epilepsy should present few problems. Our study was small and is by no means definitive. More work is needed to explore GPs' attitudes and whether they would change with time. It would also be valuable to ask older children whether they would like to see the letter and whether they understand it.

In conclusion, we recommend that paediatricians consider sending copies of outpatient letters to parents: GPs' agreement is important, and means should be developed of working between primary and secondary care to improve communication with parents.

\section{Questionnaire to parent}

Dear

We are seeking information on the value of sending a copy of the letter which is written to the GP about a child's outpatient attendance, to the parents. As a parent who should have received such a letter recently, please could you answer this brief questionnaire? It refers to your visit with to $\mathrm{Dr}$ on

Many thanks.

Yours sincerely,

Dr Tony Waterston

Consultant Community Paediatrician

Please return to Dr Tony Waterston, Consultant Community Paediatrician, Newcastle Community Health, Newcastle General Hospital, Westgate Road, Newcastle upon Tyne NE4 6BE.

Child's name

Did you receive a copy of the GP's letter?

$$
\text { Yes } \square \quad \text { No } \square
$$

Did you understand the letter?

Understood all

Some bits I didn't understand

Most of it I didn't understand

Did you have to ask someone to explain it?

Yes $\square \quad$ No $\square$

Who did you ask?

Did it help you to understand your child's problem?

$$
\begin{array}{ll}
\text { A lot } & \square \\
\text { A little } & \square \\
\text { Not at all } & \square
\end{array}
$$

Do you think a copy of the letter to the GP should normally be sent to the parent after a clinic visit? Say in your own words what you think about this idea: 


\section{Questionnaire to GP}

Dear Dr

We are seeking information on the value of sending a copy of the letter which is written to the GP about a child's outpatient attendance, to the parents. As the GP of a child whose parents should recently have received such a letter, please could you answer the brief questions below on the value of the exercise? It refers to the visit of to Dr

Many thanks.

Yours sincerely,

Dr Tony Waterston

Consultant Community Paediatrician

Please return the following to Dr Tony Waterston, Consultant Community Paediatrician, Newcastle Community Health, Newcastle General Hospital, Westgate Road, Newcastle upon Tyne NE4 6BE.

Have you received the outpatient letter about this child?

Yes $\lrcorner$

Has the parent come to see you to discuss the letter?

Yes $\lrcorner$

No $\lrcorner$

What do you think is the value of sending a copy letter to the parents?
Very useful
Indifferent
Undesirable
」

Would you be concerned if this custom was routine in paediatrics?

Yes $\lrcorner$

If yes, please give reasons:

No」

Thank you

Sample letter
Westgate Road
Newcastle upon Tyne
NE4 6BE
CHILDecretary Ext)
Date of letter
Dear
Name of patient, date of birth
On review with his mother and grandmother, I
gather that (name) has had a couple of attacks
of asthma with a cold over the past few months
and has used the nebuliser to good effect on
these occasions. He has recently been unwell
and is not eating but has not been particularly
wheezy. He is still wakeful at night and sleeps
in his mother's bed, and screams constantly if
he is put in his own room. They do not want
to leave him to cry partly because of his
distress and partly because he has a hernia
which comes out after he has been crying.
They took him to Accident and Emergency
when it was swollen recently, and I believe that
a surgical referral is under way. However, I
said that I would attempt to speed this up as
his mother has not yet received an
appointment.
On examination (name) is fairly well without
any audible wheeze, and he has a reducible
right inguinal hernia. He should continue with
the nebuliser at present and I will review him
in July.
Yours sincerely,
Dr Tony Waterston
Consultant Paediatrician
cc Mother
CMO

1 Freeman B, Negrete VF, Davis M, Korsch BM. Gaps in doctor-patient communication: doctor-patient interaction analysis. Pediatr Res 1971;5:298-311.

2 Tuckett D, Williams A. Approaches to the measurement of explanation and information giving in medical consultations: review of empirical studies. Soc $S_{i} i$ Med 1984; 18:571-80.

3 McLaren P. The right to know. BMf 1991;303:937-8.

Macfarlane A. "Personal child health records" held by parents. Arch Dis Child 1992;67:571 2

5 Rylance G. Patients' right to know. BMF 1990; 300:608-9.

6 Rutherford W, Gabriel R. Audit of outpatient letters. BMY 1991;303:968

7 Rylance G. Should audiorecordings of outpatient consultations be presented to parents? Arch Dis Child 1992;67:622-4. 